\title{
Subcortical brain atrophy persists even in HAART-regulated HIV disease
}

\author{
James T. Becker • Joanne Sanders • Sarah K. Madsen • Ann Ragin • \\ Lawrence Kingsley • Victoria Maruca $\cdot$ Bruce Cohen • Karl Goodkin • Eileen Martin • \\ Eric N. Miller • Ned Sacktor • Jeffery R. Alger • Peter B. Barker • Priyanka Saharan • \\ Owen T. Carmichael • Paul M. Thompson • Multicenter AIDS Cohort Study
}

Published online: 25 January 2011

(C) The Author(s) 2011. This article is published with open access at SpringerLink.com

\begin{abstract}
The purpose of this study was to determine the pattern and extent of caudate nucleus and putamen atrophy in HIV-infected men with well-controlled immune status and viral replication. 155 men underwent structural brain magnetic resonance imaging; 84 were HIV-infected and 71 were uninfected controls. MRI data were processed using the Fully Deformable Segmentation routine, producing volumes for the right and left caudate nucleus and putamen, and 3-D maps of spatial patterns of thickness. There was
\end{abstract}

The statistical analyses were completed by J. Becker, J. Sanders, S. Madsen, L. Kingsley. P. Saharan, and V. Maruca.

J. Sanders was formerly J. Mullen.

The Multicenter AIDS Cohort Study (MACS) includes the following investigators: Baltimore: The Johns Hopkins University Bloomberg

School of Public Health: Joseph B. Margolick (Principal Investigator), Haroutune Armenian, Barbara Crain, Adrian Dobs, Homayoon Farzadegan, Joel Gallant, John Hylton, Lisette Johnson, Shenghan Lai, Ned Sacktor, Ola Selnes, James Shepard, Chloe Thio. Chicago: Howard Brown Health Center, Feinberg School of Medicine, Northwestern University, and Cook County Bureau of Health Services: John P. Phair (Principal Investigator), Joan S. Chmiel (CoPrincipal Investigator), Sheila Badri, Bruce Cohen, Craig Conover, Maurice O'Gorman, David Ostrow, Frank Palella, Daina Variakojis, Steven M. Wolinsky. Los Angeles: University of California, UCLA Schools of Public Health and Medicine: Roger Detels (Principal Investigator), Barbara R. Visscher (Co-Principal Investigator), Aaron Aronow, Robert Bolan, Elizabeth Breen, Anthony Butch, Thomas Coates, Rita Effros, John Fahey, Karl Goodkin, Beth Jamieson, Otoniel Martínez-Maza, Eric N. Miller, John Oishi, Paul Satz, Harry Vinters, Dorothy Wiley, Mallory Witt, Otto Yang, Stephen Young, Zuo Feng Zhang. Pittsburgh: University of Pittsburgh, Graduate School of Public Health: Charles R. Rinaldo (Principal Investigator), Lawrence A. Kingsley (Co-Principal Investigator), James T. Becker, Ross D. Cranston, Jeremy J. Martinson, John W. Mellors, Anthony J. Silvestre, Ronald D. Stall. Data Coordinating Center: The Johns Hopkins University Bloomberg School of Public Health: Lisa P. Jacobson (Principal Investigator), Alvaro Munoz (Co-Principal Investigator), Stephen R. Cole, Christopher Cox, Gypsyanber D’Souza, Stephen J. Gange, Janet Schollenberger, Eric C. Seaberg, significant atrophy in the HIV-infected men in both the caudate and putamen, principally in the anterior regions. The volume of the basal ganglia was inversely associated with the time since first seropositivity, suggesting that either there is a chronic, subclinical process that continues in spite of therapy, or that the extent of the initial insult caused the extent of atrophy.

Keywords HIV· MRI · Gray matter · Basal ganglia

Sol Su. NIH: National Institute of Allergy and Infectious Diseases: Robin E. Huebner; National Cancer Institute: Geraldina Dominguez; National Heart, Lung and Blood Institute: Cheryl McDonald; National Institute of Mental Health: Pim Brouwers.

Electronic supplementary material The online version of this article (doi:10.1007/s11682-011-9113-8) contains supplementary material, which is available to authorized users.

J. T. Becker

University of Pittsburgh School of Medicine,

Pittsburgh, PA, USA

J. Sanders

Bloomberg School of Public Health,

Baltimore, MD, USA

S. K. Madsen $\cdot$ P. Saharan • P. M. Thompson

Laboratory of NeuroImaging, UCLA School of Medicine,

Los Angeles, CA, USA

A. Ragin $\cdot$ B. Cohen

Feinberg School of Medicine, Northwestern University,

Chicago, IL, USA

L. Kingsley

Graduate School of Public Health, University of Pittsburgh, Pittsburgh, PA, USA

V. Maruca

Allegheny College,

Meadville, PA, USA 


\section{Introduction}

Changes in the structure of the central nervous system have been consistently reported in HIV disease, with the caudate nucleus (CDT) and putamen (PUT) particularly vulnerable, especially in severely immunosuppressed patients (Berger and Arendt 2000; Berger and Nath 1997; Stout et al. 1998). These brain changes are in turn associated with substantial cognitive impairments that form a major public health problem related to HIV (Dal Pan et al. 1992; Hestad et al. 1993; Kieburtz et al. 1996; Levin et al. 1990; Moeller and Backmund 1990).

The development of highly active antiretroviral therapies (HAART) led to the hope that regulation of immune status and viral replication may help to ameliorate HIV-associated subcortical brain changes and subsequent cognitive impairment, but data supporting this conjecture are mixed. For example, one study reported a hypertrophy of the PUT of HIV-infected individuals with mild cognitive dysfunction, with increased putamen volume related to decreased motor speed (Castelo et al. 2007). Another recent study (Paul et al. 2008) found similar associations but in the opposite direction, and the putamen was (on average) smaller in the HIV-infected individuals.

The aim of this study was to evaluate HIV-associated changes in the CDT and PUT, in a sample of older men $(N=$ 155; age $>50$ years) recruited from the Multicenter AIDS Cohort Study (MACS). This investigation exploited sensitive new Magnetic Resonance (MR) image analysis algorithms to derive in vivo measurements of basal ganglia volumes and the spatial distribution of atrophy (Chiang et al. 2007). We assessed the effects of HIV on the presence,

K. Goodkin

University of California Los Angeles,

Los Angeles, CA, USA

E. Martin

University of Illinois at Chicago,

Chicago, IL, USA

E. N. Miller J. R. Alger

Semel Institute for Neuroscience, UCLA School of Medicine,

Los Angeles, CA, USA

N. Sacktor • P. B. Barker

The Johns Hopkins University,

Baltimore, MD, USA

O. T. Carmichael

University of California Davis,

Davis, CA, USA

\section{J. T. Becker $(\bowtie)$}

Neuropsychology Research Program,

Suite 830, 3501 Forbes Avenue,

Pittsburgh, PA 15213, USA

e-mail: beckerjt@upmc.edu location, and extent of basal ganglia atrophy in the HIV + group versus controls, and evaluated how these global and local volume reductions relate to specific clinical features, including immunological and virological status.

\section{Methods}

This study was approved by the ethical standards committee on human experimentation at each of the MACS sites. Written informed consent was obtained from all participants.

\section{Participants}

160 men were enrolled from the Cardiovascular Substudy of the MACS (Kingsley et al. 2008) and scanned between 2008 and 2009. Of the MRI data that were sent to Pittsburgh for processing, scans from 4 could not be adequately processed to obtain the mesh images; one additional participant could not tolerate the MR environment and was dropped from the study. Therefore, data from 155 participants are reported here (84 HIV+, 71 HIV-).

There were small group differences in age and education $(r$ 's .18), but none in the measures of drug use or in the racial distribution of the participants (See Table 1). Thirtyone percent of the HIV-infected men had detectable viral load, and $8 \%$ were immunosuppressed. Sixty-five of the infected men had viral loads and CD4+ cell counts available prior to the initiation of HAART. Viral loads and $\mathrm{CD} 4+$ counts were derived from biological specimens collected during MACS visits. The mean peak viral load in these infected men $(N=65)$ was $>4.5$ log units (range: $1.6-$ 6.3), and the mean $\mathrm{CD} 4+$ nadir was less than 230 (range: 15-713). We identified the date of earliest known seropositivity; for 19 of the 84 HIV-infected men (23\%), we were able to impute a date between the last known MACS visit seen seronegative and the first known MACS visit seen positive (i.e., incident infection). The remaining 65 participants were infected when they joined the MACS (i.e., prevalent infection), so their earliest known date of infection was set to their date of enrollment.

Magnetic resonance imaging

The anatomical imaging sequence was developed by the Alzheimer's Disease Neuroimaging Initiative for use with $3 \mathrm{~T}$ scanners (http://www.adni-info.org/images/stories// mritrainingmanualv1.pdf). Three of the sites used Siemens 3 T Trio scanners (maximum gradient slew rate: $200 \mathrm{mT} / \mathrm{m} / \mathrm{s}$; maximum gradient strength $40 \mathrm{mT} / \mathrm{m}$ ), with the Siemens phase-array head coil. One of the sites (Los Angeles) used a Siemens Allegra scanner. The sagittal Magnetization Prepared Rapid Acquisition Gradient Echo (MP-RAGE) sequence was: 
Table 1 Characteristics of study participants

\footnotetext{
${ }^{\text {a }}$ Percent $(\mathrm{N})$

${ }^{\mathrm{b}}$ Defined as "speed, meth or ice"

${ }^{\mathrm{c}}$ Defined as self-report, told by physician, or taking pharmacotherapy

${ }^{\mathrm{b}}$ Among men with detectable virus
}

\begin{tabular}{|c|c|c|c|}
\hline & HIV - & HIV + & $(r, p)$ \\
\hline $\mathrm{N}=$ & 71 & 84 & \\
\hline Age & $57.9(6.3)$ & $55.8(4.9)$ & $-.18, .02$ \\
\hline Education & $16.4(2.55)$ & $15.04(2.6)$ & $-.17, .04$ \\
\hline Race $(\%(N)$ white $)$ & $82(58)$ & $74(62)$ & $.09,>.20$ \\
\hline Handedness $(\%(\mathrm{~N})$ right-handed $)$ & $87(59)$ & $87(71)$ & $.01,>.20$ \\
\hline Crack cocaine $^{\mathrm{a}}$ & $16(11)$ & $24(20)$ & $.10, .20$ \\
\hline Cocaine $^{\mathrm{a}}$ & $7(12)$ & $27(23)$ & $.13, .12$ \\
\hline Uppers ${ }^{\mathrm{a}, \mathrm{b}}$ & $7(5)$ & $17(14)$ & $.15, .07$ \\
\hline $\mathrm{CESD} \geq 16(\mathrm{~N}(\%))^{\mathrm{a}}$ & $18(13)$ & $17(14)$ & $-.02, .79$ \\
\hline Diabetes $^{\mathrm{a}, \mathrm{c}}$ & $17(12)$ & $12(10)$ & $-.07, .23$ \\
\hline High blood pressure ${ }^{a, c}$ & $42(30)$ & $43(36)$ & $.01, .82$ \\
\hline $\mathrm{CD} 4+<200(\mathrm{~N}(\%))^{1}$ & $\mathrm{n} / \mathrm{a}$ & $8(6)$ & - \\
\hline Current detectable viral load $(\mathrm{N}(\%))^{\mathrm{a}}$ & $\mathrm{n} / \mathrm{a}$ & $31(24)$ & - \\
\hline CD4+ current & $\mathrm{n} / \mathrm{a}$ & $540(270)$ & - \\
\hline CD4+ nadir & $\mathrm{n} / \mathrm{a}$ & $222(135)$ & - \\
\hline HIV RNA current ${ }^{\mathrm{d}}$ & $\mathrm{n} / \mathrm{a}$ & $3.22(1.1)$ & - \\
\hline HIV RNA peak & $\mathrm{n} / \mathrm{a}$ & $4.60(1.2)$ & - \\
\hline HAART use $(\mathrm{N}(\%))$ & $\mathrm{n} / \mathrm{a}$ & $71(88)$ & - \\
\hline CDT volume & $1.24(.14)$ & $1.12(.16)$ & $-.39,<.001$ \\
\hline Left & $.69(.08)$ & $.61(.10)$ & $-.40,<.001$ \\
\hline Right & $.54(.07)$ & $.49(.07)$ & $-.32,<.001$ \\
\hline PUT volume & $1.05(.20)$ & $.89(.16)$ & $-.39,<.001$ \\
\hline Left & $.67(.12)$ & $.57(.11)$ & $-.39,<.001$ \\
\hline Right & $.38(.09)$ & $.32(.06)$ & $-.35,<.001$ \\
\hline Basal ganglia summary & $2.29(.32)$ & $2.02(.31)$ & $-.41,<.001$ \\
\hline
\end{tabular}

FOV-256 mm; slices $=160 ; \mathrm{TR}=2300 \mathrm{~ms} ; \mathrm{TE}=2.91 \mathrm{~ms}$; $\mathrm{TI}=900 \mathrm{~ms}$; Flip angle $=9^{\circ}$; thickness $=1.2 \mathrm{~mm}$.

We used the Fully Deformable Segmentation (Carmichael et al. $2007 \mathrm{a}, \mathrm{b})$ routine, first stripping the skull, scalp, and extraneous tissue from the brain using a recursive form of the Brain Extraction Tool (Fagiolo et al. 2008). Once the brain was extracted, a high-resolution single-subject average MRI scan (Holmes et al. 1998) was normalized to the subject space using a fully-deformable registration method (Chen 1999). The deformation parameters from this step are used to align the template masks of the CDT and PUT to the subject brain. Because the globus pallidus was difficult to identify reliably, we did not include this structure in the analysis. The aligned masks were used to extract the volume of the ROIs, and to generate surface maps. This method has been validated against manually derived data in patients with HIV disease (Carmichael et al. 2007a, b).

Anatomical mesh modeling methods were then used to match equivalent CDT and PUT surface points obtained from the automated tracings, across participants and groups (Thompson et al. 2004). The surface contours were made uniform by modeling them as a 3-D parametric surface mesh (Thompson et al. 1996) allowing measure- ments to be made at corresponding surface locations in each participant. This procedure also allows the averaging of CDT and PUT surface morphology across all individuals belonging to a group and records the amount of variation between corresponding surface points relative to the group averages.

To assess global atrophy of the CDT and PUT, the volume of each structure, measured as part of the tissue segmentation routine, was expressed as a percent of the total brain volume (see Table 2). We created a single summary variable to reflect the total volume of these two basal ganglia subregions by summing the four individual values, and dichotomized their total volume based on the median of all 155 participants. To measure local atrophy, a 3-D curve was derived from each individual CDT and PUT surface mesh down their central axis. The distance of each surface point from this centerline measures the radial size of the individual structures, and statistical maps were generated showing local group differences. Regression analyses were run at each surface point to map linkages with radial size, and the local $p$ value was plotted onto the surface at each point. Overall corrected $p$ values were also assigned to the maps using permutation testing to give an overall 
Table 2 Factors associated with basal ganglia volume (percent $(\mathrm{N}))$
${ }^{\text {a }}$ Any use in the last 5 years

${ }^{\mathrm{b}}$ CES-D score $>16$

${ }^{\mathrm{c}} \chi^{2}$, Odds Ratio and $p$ for dichotomous variables; $t, r$ and $p$ for continuous variables

\begin{tabular}{lccc}
\hline \multirow{2}{*}{ Factors } & \multicolumn{2}{c}{ Total basal ganglia volume } & \\
\cline { 2 - 4 } & Above median & Below median & Statistics $^{\mathrm{c}}$ \\
\hline $\mathrm{N}=$ & 77 & 78 & \\
Group (HIV +) & $34(26)$ & $58(74)$ & $25.7,5.69,<.001$ \\
Race (Non-White) & $27(21)$ & $18(14)$ & $1.93, .58, .12$ \\
Crack use $^{\mathrm{a}}$ & $20(15)$ & $21(16)$ & $.03,1.07,>.10$ \\
Other cocaine $^{\mathrm{a}}$ & $21(16)$ & $24(19)$ & $.28,1.23,>.10$ \\
Uppers $^{\mathrm{a}}$ & $10(8)$ & $14(11)$ & $.50,1.42,>.10$ \\
Diabetes $^{\mathrm{b}}$ & $13(10)$ & $15(12)$ & $.183,1.21,>.10$ \\
Depression $^{\mathrm{b}}$ & $17(13)$ & $18(14)$ & $.03,1.08,>.10$ \\
Age & $57.4(6.1)$ & $56.7(4.5)$ & $.78,-.06,>.10$ \\
Education $_{\text {Systolic BP }}$ & $16.2(2.7)$ & $16.1(2.5)$ & $.13,-.01,>.10$ \\
Diastolic BP & $129.0(14.8)$ & $77.1(9.4)$ & $.22,-.02,>.10$ \\
Fasting glucose & $78.1(10.0)$ & $107.8(60)$ & $.56(-.05),>.10$ \\
Hemoglobin A1C & $103.4(15.8)$ & $56.9(14.7)$ & $-.57, .05,>.10$ \\
Total cholesterol & $57.0(10.8)$ & $200.2(58)$ & $.50,-.04,>.10$ \\
HDL & $188.1(33)$ & $494.4(171)$ & $-1.60, .13, .11$ \\
LDL & $504.8(134)$ & $111.7(36)$ & $.42,-.03,>.10$ \\
\hline
\end{tabular}

significance value for the effect, adjusting for multiple comparisons (Lin et al. 2005; Thompson et al. 2004)

\section{Results}

The volumes of the CDT and PUT, adjusted for total brain volume ((region/total)*100), were significantly smaller in the HIV-infected men than in the controls (see Table 1). Table 2 shows the unadjusted risks of having a smaller total basal ganglia volume (i.e., below the median of all 155 subjects) as a function of a range of participant characteristics. Only HIV serostatus was significantly linked to the size of the basal ganglia overall; none of the other betweengroup differences were significant.

We then examined the relationship between HIVassociated factors and the summary volume. For these analyses the basal ganglia summary variable was dichotomized at the median of the HIV-infected participants only. The data were divided based on the group median because we were interested in examining the factors associated with atrophy in the HIV-infected men. We found no significant differences between the two groups of infected men in terms of their current CD4+ cell count or HIV viral load, or the nadir CD4+ cell count and peak HIV viral load (see Table 3). There was no effect of using antiretroviral medications with greater CNS penetrance on basal ganglia volume (Letendre et al. 2008). We did find a significant difference in the number of years of infection, such that here was a trend for the time since seroconversion (i.e., $n=19$ ) to be longer among the men with smaller basal ganglia; the effect size did not differ from that of the men with prevalent infection (i.e., $r=.39$ vs. $r=.45$ ) (See Supplementary Figure E-1). We regressed the basal ganglia summary volume on age, race, and time since first known seropositivity in all $84 \mathrm{HIV}$-infected men. Only the time variable was related to volume $(\beta=-.48, \mathrm{t}(83)=4.20, p<.001)$, and neither age $(\beta=-.11, p>.10)$ nor race $(\beta=-.12, p>.10)$ were associated with basal ganglia volume. When we compared the HIV-infected men as a function of the time since first seropositivity (Table 4), only the summary basal ganglia volume and age differed among the groups (See also Supplemental Figure E-2).

Figure 1 shows the regions of the CDT and PUT where the mean radial size of these structures was lower in the HIV-infected than in the control group (See also Supplemental Figure E-3). The level of local atrophy was significantly associated with serostatus (all corrected $p$ values, computed by permutation testing were less than 0.001 , see Supplemental Table E-1). There were no regions of local expansion that reached statistical significance for either the caudate or the putamen.

Among the HIV-infected men, we found a significant effect of time since first confirmed seropositivity (as above) and local shape differences (See Supplemental Table E-1). The spatial distribution of the atrophy is not uniform, with CDT atrophy primarily in the anterior regions, whereas the PUT atrophy is more evenly distributed. The pattern of local atrophy as a function of time since seropositivity resembles that of the HIV effect, but to a lesser extent. 
Table 3 Factors associated with HIV disease and basal ganglia volumes

\begin{tabular}{|c|c|c|c|}
\hline & \multicolumn{2}{|c|}{ Basal ganglia volumes } & \multirow[b]{2}{*}{$(t, r, p)$} \\
\hline & Above median & Below median & \\
\hline $\mathrm{N}$ & 42 & 42 & \\
\hline \multicolumn{4}{|l|}{ CD4 cell counts } \\
\hline Current & $515.7(278)$ & $566.3(262)$ & $-.82, .09,>.10$ \\
\hline Nadir $^{\mathrm{a}}$ & $213.4(138)$ & $238.5(114)$ & $-.80, .10,>.10$ \\
\hline \multicolumn{4}{|l|}{ HIV viral load } \\
\hline Current & $1.94(.79)$ & $2.18(1.06)$ & $-1.17, .13,>.10$ \\
\hline Peak $^{\mathrm{b}}$ & $5.03(.56)$ & $4.92(.66)$ & $.68,-.09,>.10$ \\
\hline Years since first positive visit ${ }^{\mathrm{c}}$ & $13.1(8.6)$ & $20.3(5.6)$ & $4.53, .45,<.001$ \\
\hline Years since seroconversion $(\mathrm{n}=19)$ & $12.0(6.8)$ & $16.8(4.8)$ & $1.74, .39, .10$ \\
\hline Use of HAART (Percent (N)) & $83(35)$ & $74(31)$ & $1.20,-.12, .55^{\mathrm{d}}$ \\
\hline Rank of HAART CNS penetrance & $1.71(.76)$ & $1.63(.66)$ & $0.473, .003, .648$ \\
\hline
\end{tabular}

${ }^{\mathrm{a}}$ Lowest measured CD4+ cell count prior to HAART $(n=65)$

${ }^{\mathrm{b}}$ Highest HIV RNA prior to HAART $(n=65)$

${ }^{\mathrm{c}}$ Visit with first confirmed HIV seropositivity. Includes both prevalent and incident cases $(n=84)$

${ }^{\mathrm{d}} \chi^{2}, r, p$

\section{Discussion}

The results of this study show that in the era of HAART, among HIV-infected individuals with access to medical care, there is still measurable atrophy in subcortical brain structures. We present here for the first time, selective patterns of atrophy in the 3-D surface contours of the CDT and PUT as a function of HIV disease. We have previously found alterations in the basal ganglia using tensor-based analyses (Chiang et al. 2007; Lepore et al. 2008), but this is the first description of the local contractions in the shape of these structures. Furthermore, we have linked the location of the atrophy to the time since first seropositivity. Thus, at both a global and local level, we found that basal ganglia volume remains exquisitely sensitive to the presence of the HIV virus. Furthermore, the longer an individual is infected with HIV, the greater the loss in volume. The explanation for these findings cannot be conclusively determined in this cross-sectional study, but there are at least two general hypotheses that offer important clues for our understanding of the epidemic.

First, the "time" variable reflects both incident infection (i.e., with a better estimate of date of infection) and prevalent infection (where the infection occurred at some time prior to enrollment in the MACS). The most parsimonious explanation of the time effect is that it is related to the enrollment of new recruits into the MACS. Volunteers entered in three waves: 1984/85, 1987/90, and in 2001/03 (primarily from racial/ethnic minorities); the men joining in 2001-2003 were generally already infected. The majority of our seropositive volunteers $(57 \%)$ were either infected at the time of enrollment 25 years ago, or were infected soon thereafter. A smaller group became infected in the following 10 years of the study, and the remainder $(27 \%)$ either entered the study with HIV

Table 4 Participant characteristics as a function of duration of infection

\begin{tabular}{|c|c|c|c|c|}
\hline & Less than 10 years & $10-20$ years & Greater than 20 years & $(\mathrm{F}, r, p)$ \\
\hline $\mathrm{N}$ & 23 & 13 & 48 & \\
\hline Time since infection ${ }^{\mathrm{a}}$ & $4.26(.86)$ & $16.2(2.7)$ & $22.7(.57)$ & $1787, .99,<.001$ \\
\hline Basal ganglia volume & $2.25(.31)$ & $2.00(.28)$ & $1.91(.25)$ & $12.6, .56,<.001$ \\
\hline Age & $54.3(3.0)$ & $56.4(3.9)$ & $57.2(4.1)$ & $4.71, .32,<.001$ \\
\hline \multicolumn{5}{|l|}{ CD4+ cell count } \\
\hline Current & $503.3(273)$ & $568.1(279)$ & $549.0(272)$ & $.28, .09,>.10$ \\
\hline Nadir $^{\mathrm{b}}$ & $271.8(70.0)$ & $242.2(134)$ & $221.1(126)$ & $.40, .11,>.10$ \\
\hline \multicolumn{5}{|l|}{ HIV viral load } \\
\hline Current & $2.12(1.0)$ & $2.01(.92)$ & $2.04(.92)$ & $.08, .05,>.10$ \\
\hline Peak $^{\mathrm{c}}$ & $4.89(.35)$ & $5.22(.41)$ & $4.90(.67)$ & $1.36, .21,>.10$ \\
\hline On HAART (percent $(\mathrm{N})$ ) & 83 (19) & $92(12)$ & $73(35)$ & $1.13,-.12, .29^{\mathrm{d}}$ \\
\hline
\end{tabular}

\footnotetext{
${ }^{a}$ Visit with first confirmed HIV seropositivity. Includes both prevalent and incident cases $(n=84)$

${ }^{\mathrm{b}}$ Lowest measured CD4+ cell count prior to HAART $(n=65)$

${ }^{\mathrm{c}}$ Highest HIV RNA prior to HAART $(n=65)$

${ }^{\mathrm{d}} \chi^{2}, r, p$
} 


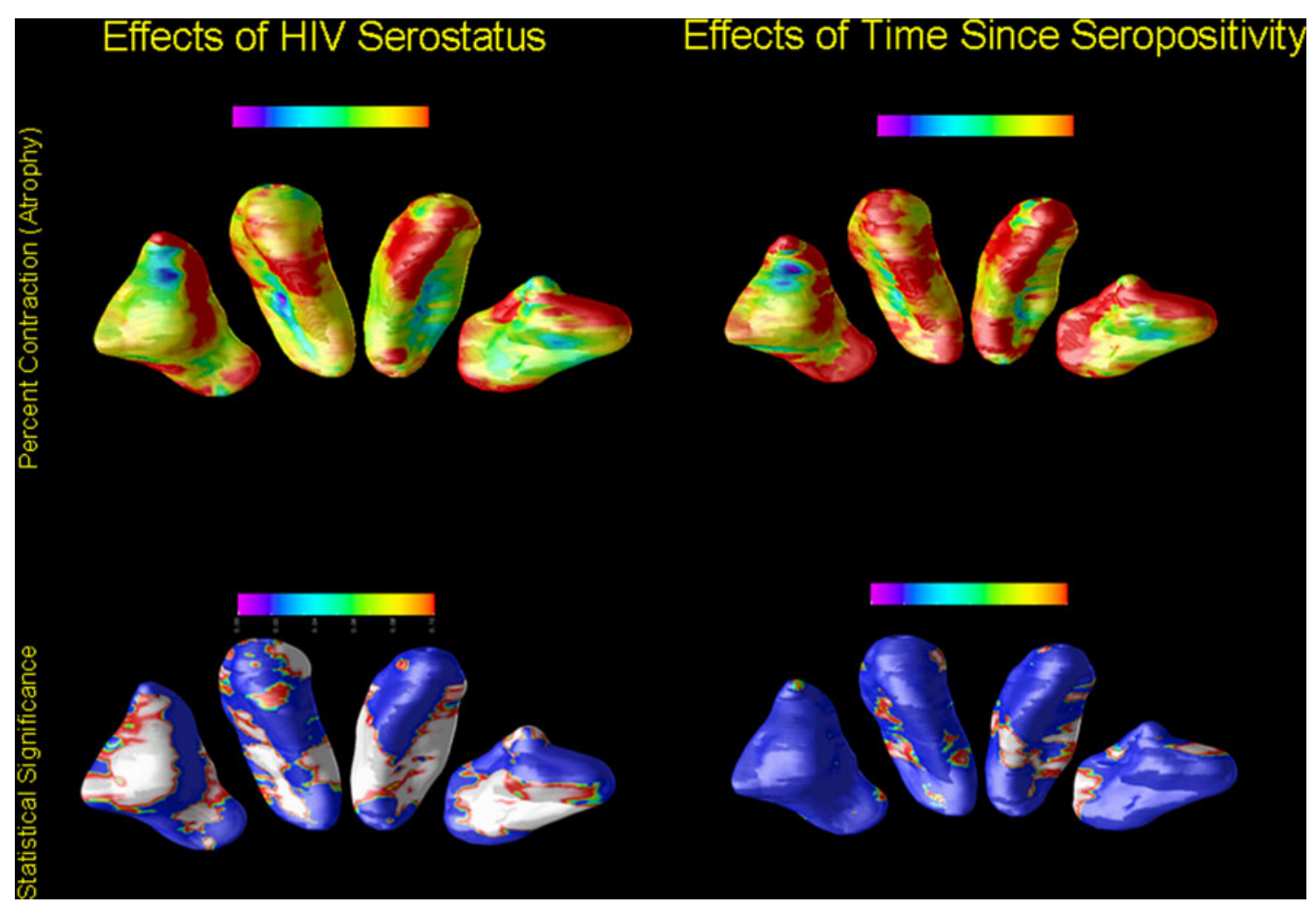

Fig. 1 The regions of the CDT and PUT where the mean radial size of these structures was lower in the HIV-infected versus the control group. The images show the inferior surfaces of both the caudate and putamen in radiological orientation (i.e., looking towards the reader); the areas separated in the figure to ease viewing, and do not represent the actual spatial contiguity of the regions. The top row of the figure shows the areas of contraction as a function of serostatus (left) and

infection or seroconverted during that time period. The group with the longest duration of infection will have had the longest time without any treatment, will have had some time with non-HAART monotherapy, and will have been among the group that managed to survive the infection. The group that became infected most recently had the opportunity to receive HAART as the first line of therapy, and likely had therapy initiated at an earlier point in the natural history of the infection. This interpretation suggests that earlier and more aggressive intervention may help protect the brain from long-term effects of the virus (Marcondes et al. 2009). However, a recent cross-sectional study (Cohen et al. 2010) that found that nadir CD4+ cell counts and duration of infection were related to cortical volume, whereas caudate nucleus volumes were related to current plasma viral load. When we examined the association between the current HIV viral load and basal ganglia volume among the men with measureable virus in plasma, the correlation was modest, at best $(r=-.21, p=.33, n=23)$. The differences in the analysis technique, particularly the method of the spatial normalization of the scans, may be one source of difference between studies. time since first seropositivity (right). The areas of red have no significant contraction, and those with purple have $\sim 15 \%$ contraction. The bottom row of the figure shows the local significance values from the test for group differences in the degree of atrophy for the CDT and PUT. Areas of dark blue have no significant change (by permutations testing) and those marked in white have highly significant effects (P's $<.01$ and smaller)

Alternatively, the effect of time may be the consequence of a low grade, chronic process that alters brain structure even when peripheral measures of viral load and immunocompetence are within acceptable limits (Chang et al. 2003; Chang et al. 2002; Ernst and Chang 2004). There may be an ongoing process related to HIV disease, which was not altered by the changing dynamics of the infection, and which may not be reflected in the clinical quiescent period (Cysique et al. 2005). Consistent with this idea was the finding that the regions of the basal ganglia that were significantly correlated with duration of infection were similar in both location and extent of contraction to those areas that were related to HIV disease overall. The major differences between the maps were in the local $p$-values, which were influenced by the sample size used for the two analyses.

We favor the first of these hypotheses in part because it is more parsimonious, but also because it seems to be more in line with the accumulating data that suggest that what we are observing is the damage done to the CNS prior to the initiation of HAART. For example, data from a study in China have found that while cognitive functions 
improve with anti-retroviral therapy, these patients did not return to normal (Cysique et al. 2010). Distinguishing between these two hypotheses is critical for understanding the effects of HIV on the CNS, and for developing rational treatment policies. However, this will require longitudinal data from HIV-infected individuals with a range of time-since-infection, and a substantial group with exposure only to HAART.

Several points should be considered when interpreting these data. The MACS Cardiovascular substudy was initiated in 2004 and included men age $\geq 40$ years, with no self-reported history of clinical heart disease or cerebrovascular disease; all of the participants in this MRI study were at least 50 years old. Thus, these are individuals who, by and large, survived for 15-25 years with the virus, without developing significant age- and treatment-related comorbidities that are becoming increasingly common as the epidemic ages. None of the men in the study met criteria for HIV-Associated Dementia, although $9 / 84(11 \%)$ performed in the mildly impaired range (i.e., asymptomatic impairment or minor neurocognitive disorder) (Antinori et al. 2007). Furthermore, we have noted previously (Becker et al. 2009), that the overall health of the HIV-infected men in this study is generally better than that of the seronegative control participants. Consequently, the men with HIV disease likely had fewer vascular risk factors for cognitive impairment and brain atrophy due to aggressive use of statins and antihypertensive medications, and they are also individuals who may have a different physiological resistance relative to individuals who succumbed to HIV. Finally, the HIVinfected men who were enrolled in the MACS in 2001-2003 and who were on HAART at the time that they enrolled also: a) had to have had a known date of HAART initiation, b) could not have had an AIDS diagnosis before (or coincident with) the initiation of HAART, and c) had to have had HIV RNA and CD4+ data within 4 months before HAART initiation. This means that those men who did not have as good access to care, or who were not as healthy were not included in this recruitment wave.

These findings are consistent with our prior studies using a different cohort of HIV-infected individuals who had poorer health-related outcomes. For example, we found significant bilateral brain atrophy that was correlated with cognitive impairment and CD4+ cell counts (Chiang et al. 2007), while others (Paul et al. 2008) report that the basal ganglia were smaller, although not significantly, among HIV + individuals. However, the younger age of that sample (mean $\sim 38$ years) suggests a shorter duration of infection, which may be linked to less volume loss. The findings of increased brain region size (Castelo et al. 2007) are more difficult to reconcile, and there may have been some differences in the sampling frame relative to the present study that may have accounted for the differences between the studies.
HIV viral proteins are neurotoxic, so the volumetric differences found here may reflect neuronal loss, reduced dendritic complexity, synaptic loss (Wiley et al. 1991), and associated white matter degeneration. HAART medications often fail to significantly penetrate the blood brain barrier (Cysique et al. 2004), so brain atrophy may still occur in patients treated with antiretroviral medication. The MACS has previously shown that levels of viremia and CD4+ cell count predict the onset of HIV-Associated Dementia and neuropathy prior to the use of HAART (Childs et al. 1999). The data that we present here suggest that the overall duration of infection may be an important predictor of the extent of CNS damage - even if viral load and CD4+ cell counts are currently under control. Our study participants who have been infected for more than 15 years would have suffered a progressive loss of gray and white matter, and specific loss in the CDT (Stout et al. 1998). With the advent of effective therapy, this loss may have slowed, but was not arrested. The use of medications with higher CNS penetrance would have offered greater, but not complete protection, to the CNS (Marra et al. 2003; Marra et al. 2009). Thus, we would expect that with earlier and better control of viral replication, the CNS complications of HIV disease, especially those related to CNS structure, will be greatly attenuated.

While there are limitations to the sample of participants used in this study, there are important aspects of this group that render these data unique. Because of the extensive follow-up in the MACS, as many as 25 years of data are available on the participants in the study. Viral load and CD4+ cell counts were measured throughout the history of their infection. The men in the study had no clinically manifest cardiovascular disease at the time of their scan. While this biases the sample somewhat, the volunteers in this study provide a rich substrate to evaluate effects of incident CVD on CNS structure and function in the context of HIV disease.

Acknowledgements The authors are grateful to the participants and the staff of the Multicenter AIDS Cohort Study for the additional time and effort that they contributed towards the successful completion of this project. This study was supported in part by funds from the National Institute for Allergy and Infectious Diseases to the collaborating MACS sites: UO1-AI-35042, 5-MO1-RR-00052 (GCRC), UO1-AI-35043, UO1-AI-37984, UO1-AI-35039, UO1-AI35040, UO1-AI-37613, UO1-AI-35041. The NP Working Group is grateful to the Executive Advisory Committee of the MACS, and particularly Dr. Roger Detels, for providing the funding of this project. SM, PS, and PT are supported in part by EB008281 and EB007813 (to PT). The funding agencies had no role in the design, acquisition, analysis or reporting the findings of this research. The authors would like to thank Wei Wang for running the FDS code.

Open Access This article is distributed under the terms of the Creative Commons Attribution Noncommercial License which permits any noncommercial use, distribution, and reproduction in any medium, provided the original author(s) and source are credited. 


\section{References}

Antinori, A., Arendt, G., Becker, J. T., Brew, B. J., Byrd, D. A., Cherner, M., et al. (2007). Updated research nosology for HIV-associated neurocognitive disorders. Neurology, 69(18), 1789-1799.

Becker, J. T., Kingsley, L., Mullen, J., Cohen, B., Martin, E., Miller, E. N., et al. (2009). Vascular risk factors, HIV serostatus, and cognitive dysfunction in gay and bisexual men. Neurology, 73(16), 1292-1299.

Berger, J. R., \& Arendt, G. (2000). HIV dementia: The role of the basal ganglia and dopaminergic systems. Journal of Psychopharmacology, 14(3), 214-221.

Berger, J. R., \& Nath, A. (1997). HIV Dementia and the basal ganglia. Intervirology, 40, 122-131.

Carmichael, O. T., Kuller, L. H., Lopez, O. L., Thompson, P. M., Dutton, R. A., Lu, A., et al. (2007a). Cerebral ventricular changes associated with transitions between normal cognitive function, mild cognitive impairment, and dementia. Alzheimer Disease and Related Disorders, 21(1), 14-24.

Carmichael, O. T., Kuller, L. H., Lopez, O. L., Thompson, P. M., Dutton, R. A., Lu, A., et al. (2007b). Acceleration of cerebral ventricular expansion in the Cardiovascular Health Study. Neurbiol Aging, 28(9), 1316-1321.

Castelo, J. M., Courtney, M. G., Melrose, R. J., \& Stern, C. E. (2007). Putamen hypertrophy in nondemented patients with human immunodeficiency virus infection and cognitive compromise. Archives of Neurology, 64(9), 1275-1280.

Chang, L., Ernst, T., Ames, N., Walot, I., Jovicich, J., DeSilva, M., et al. (2003). Persistent brain abnormalities in antiretroviral-naive HIV patients 3 months after HAART. Antiviral Therapy, 8(1), 17-26.

Chang, L., Ernst, T., Witt, M. D., Ames, N., Galefsky, M., \& Miller, E. (2002). Relationships among brain metabolics, cognitive function, and viral loads in antiretroviral-naive HIV patients. Neuroimage, 17(3), 1638-1648.

Chen, M. (1999). 3-D deformable registration using a statistical atlas with applications in medicine. Doctoral dissertation. Pittsburgh, PA: Carnegie Mellon University

Chiang, M. C., Dutton, R. A., Hayashi, K. M., Toga, A. W., Lopez, O. L., Aizenstein, H. J., et al. (2007). 3D pattern of brain atrophy in HIV/AIDS visualized using tensor-based morphometry. Neuroimage, 34(1), 44-60.

Childs, E. A., Lyles, R. H., Selnes, O. A., Chen, B., Miller, E. N., Cohen, B. A., et al. (1999). Plasma viral load and CD4 lymphocytes as predictive markers for HIV-associated dementia and sensory neuropathy. Neurology, 52(3), 607-613.

Cohen, R. A., Harezlak, J., Schifitto, G., Hana, G., Clark, U., Gongvatana, A., et al. (2010). Effects of nadir CD4 count and duration of human immunodeficiency virus infection on brain volumes in the highly active antiretroviral therapy era. Journal of Neurovirology, 16(1), 25-32.

Cysique, L. A., Brew, B. J., Halman, M., Catalan, J., Sacktor, N., Price, R. W., et al. (2005). Undetectable cerebrospinal fluid HIV RNA and beta-2 microglobulin do not indicate inactive AIDS dementia complex in highly active antiretroviral therapy-treated patients. Journal of Acquired Immune Deficiency Syndromes, 39(4), 426-429.

Cysique, L. A., Letendre, S. L., Ake, C., Jin, H., Franklin, D. R., Gupta, S., et al. (2010). Incidence and nature of cognitive decline over 1 year among HIV-infected former plasma donors in China. AIDS, 24(7), 983-990.

Cysique, L. A. J., Maruff, P., \& Brew, B. J. (2004). Antiretroviral therapy in HIV infection. Archives of Neurology, 61, 1699-1704.

Dal Pan, J. G., McArthur, J., Aylward, E., Selnes, O. A., NanceSproson, T. E., Kumar, A. J., et al. (1992). Patterns of cerebral atrophy in HIV1-infected individuals: Results of a quantitative MRI analysis. Neurology, 42, 2125-2130.
Ernst, T., \& Chang, L. (2004). Effect of aging on brain metabolism in antiretroviral-naive HIV patients. AIDS, 18(Suppl 1), 61-67.

Fagiolo, G., Waldman, A., \& Hajnal, J. V. (2008). A simple procedure to improve FMRIb software library brain extraction tool performance. The British Journal of Radiology, 81(963), 250-251.

Hestad, K., McArthur, J. H., Dal Pan, G. J., Selnes, O. A., NanceSproson, T. E., Aylward, E., et al. (1993). Regional brain atrophy in HIV-1 infection: Association with specific neuropsychological test performance. Acta Neurologica Scandinavica, 88, 112-118.

Holmes, C. J., Hoge, R., Collins, L., Woods, R., Toga, A. W., \& Evans, A. C. (1998). Enhancement of MR images using registration for signal averaging. Journal of Computer Assisted Tomography, 22(2), 324-333.

Kieburtz, K., Ketonen, L., Cox, C., Grossman, H., Holloway, R., Booth, H., et al. (1996). Cognitive performance and regional brain volume in human immunodeficiency virus type 1 infection. Archives of Neurology, 53(2), 155-158.

Kingsley, L. A., Cuervo-Rojas, J., Munoz, A., Palella, F. J., Post, W., Witt, M. D., et al. (2008). Subclinical coronary atherosclerosis, HIV infection and antiretroviral therapy: Multicenter AIDS Cohort Study. AIDS, 22(13), 1589-1599.

Lepore, N., Brun, C. A., Chou, Y. Y., Chiang, M. C., Dutton, R. A., Hayashi, K. M., et al. (2008). Generalized tensor-based morphometry of HIV/AIDS usingmultivariate statistics on strain matrices and their application to HIV/AIDS. IEEE Transactions on Medical Imaging, Special Issue on Computational Neuroanatomy, 27(1), 129-141.

Letendre, S., Marquie-Beck, J., Capparelli, E., Best, B., Clifford, D., Collier, A. C., et al. (2008). Validation of the CNS penetration-effectiveness rank for quantifying antiretroviral penetration into the central nervous system. Archives of Neurology, 65(1), 65-70.

Levin, H. S., Williams, D. H., Boruncki, M. J., Hillman, G. R., Williams, J. B., Guinto, F. C., et al. (1990). Magnetic resonance imaging and neuropsychological findings in human immunodeficiency virus infection. JAIDS, 3, 752-762.

Lin, J. J., Salamon, N., Lee, A. D., Dutton, R. A., Geaga, J. A., Hayashi, K. M., et al. (2005). Three-dimensional preoperative maps of hippocampal atrophy predict surgical outcomes in temporal lobe epilepsy. Neurology, 65(7), 1094-1097.

Marcondes, M. C., Flynn, C., Huitron-Rezendiz, S., Watry, D. D., Zandonatti, M., \& Fox, H. S. (2009). Early antiretroviral treatment prevents the development of central nervous system abnormalities in simian immunodeficiency virus-infected rhesus monkeys. AIDS, 23(10), 1187-1195.

Marra, C. M., Lockhart, D., Zunt, J. R., Perrin, M., Coombs, R. W., \& Collier, A. C. (2003). Changes in CSF and plasma HIV-1 RNA and cognition after starting potent antiretroviral therapy. Neurology, $60,1388-1390$

Marra, C. M., Zhao, Y., Clifford, D. B., Letendre, S., Evans, S., Henry, K., et al. (2009). Impact of combination antiretroviral therapy on cerebrospinal fluid HIV RNA and neurocognitive performance. AIDS, 23(11), 1359-1366.

Moeller, A. A., \& Backmund, H. C. (1990). Ventricle brain ratio in the clinical course of HIV infection. Acta Neurologica Scandinavica, $81,512-515$.

Paul, R. H., Ernst, T., Brickman, A. M., Yiannoutsos, C. T., Tate, D. F., Cohen, R. A., et al. (2008). Relative sensitivity of magnetic resonance spectroscopy and quantitative magnetic resonance imaging to cognitive function among nondemented individuals infected with HIV. Journal of the International Neuropsychological Society, 14(5), 725-733.

Stout, J. C., Ellis, R. J., Jernigan, T. L., Archibald, S. L., Abramson, I., Wolfson, T., et al. (1998). Progressive cerebral volume loss in Human Immunodeficiency Virus infection: A 
longitudinal volumetric magnetic resonance imaging study. Archives of Neurology, 55, 161-168.

Thompson, P. M., Hayashi, K. M., Simon, S., Geaga, J., Hong, M. S., Sui, Y., et al. (2004). Structural abnormalities in the brain of human subjects who use methamphetamine. The Journal of Neuroscience, 24(26), 6028-6036.
Thompson, P. M., Schwartz, C., \& Toga, A. W. (1996). Highresolution random mesh algorithms for creating a probabilistic 3D surface atlas of the humanbrain. Neuroimage, 3, 19-34.

Wiley, C. A., Masliah, E., Morey, M., Lemere, C., DeTeresa, R., Grafe, M., et al. (1991). Neocortical damage during HIV infection. Annals of Neurology, 29, 651-657. 